\title{
Correction to: Design and experimental validation of a nonlinear controller for underactuated surface vessels
}

Wei Xie - Joel Reis · David Cabecinhas •

Carlos Silvestre $(\mathbb{D}$

Published online: 3 March 2021

(C) Springer Nature B.V. 2021

Correction to: Nonlinear Dyn (2020) 102:2563-2581

https://doi.org/10.1007/s11071-020-06058-8

The correct Figs. 2, 3, 4, 5, and 6 are shown in the correction article.

The original article has been corrected.

The original article can be found online at https://doi.org/10. 1007/s11071-020-06058-8.

W. Xie · J. Reis · C. Silvestre $(\varangle)$

Faculty of Science and Technology, University of Macau,

Taipa, Macau, China

e-mail: csilvestre@um.edu.mo

D. Cabecinhas

Institute for Systems and Robotics, Instituto Superior Técnico, Universidade de Lisboa, 1049-001 Lisbon, Portugal 
Fig. 2 Simulated exogenous perturbations
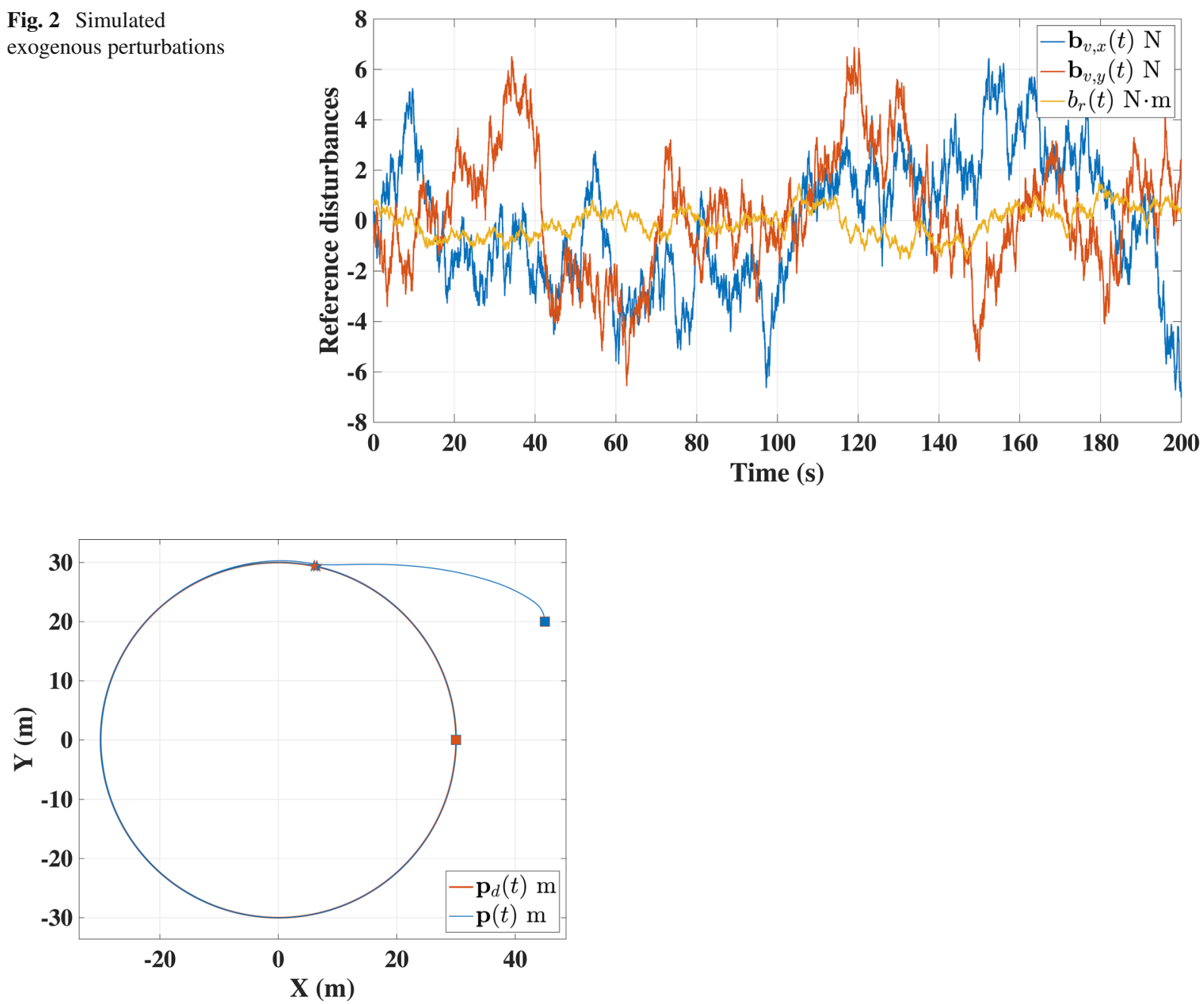

Fig. 3 Top view of desired and actual trajectories. Squares and stars mark the start and end points, respectively, of each trajectory 
Fig. 4 Evolution of the error variables

Fig. 5 Thrust actuation versus speed profile

Fig. 6 Torque actuation versus angular velocity
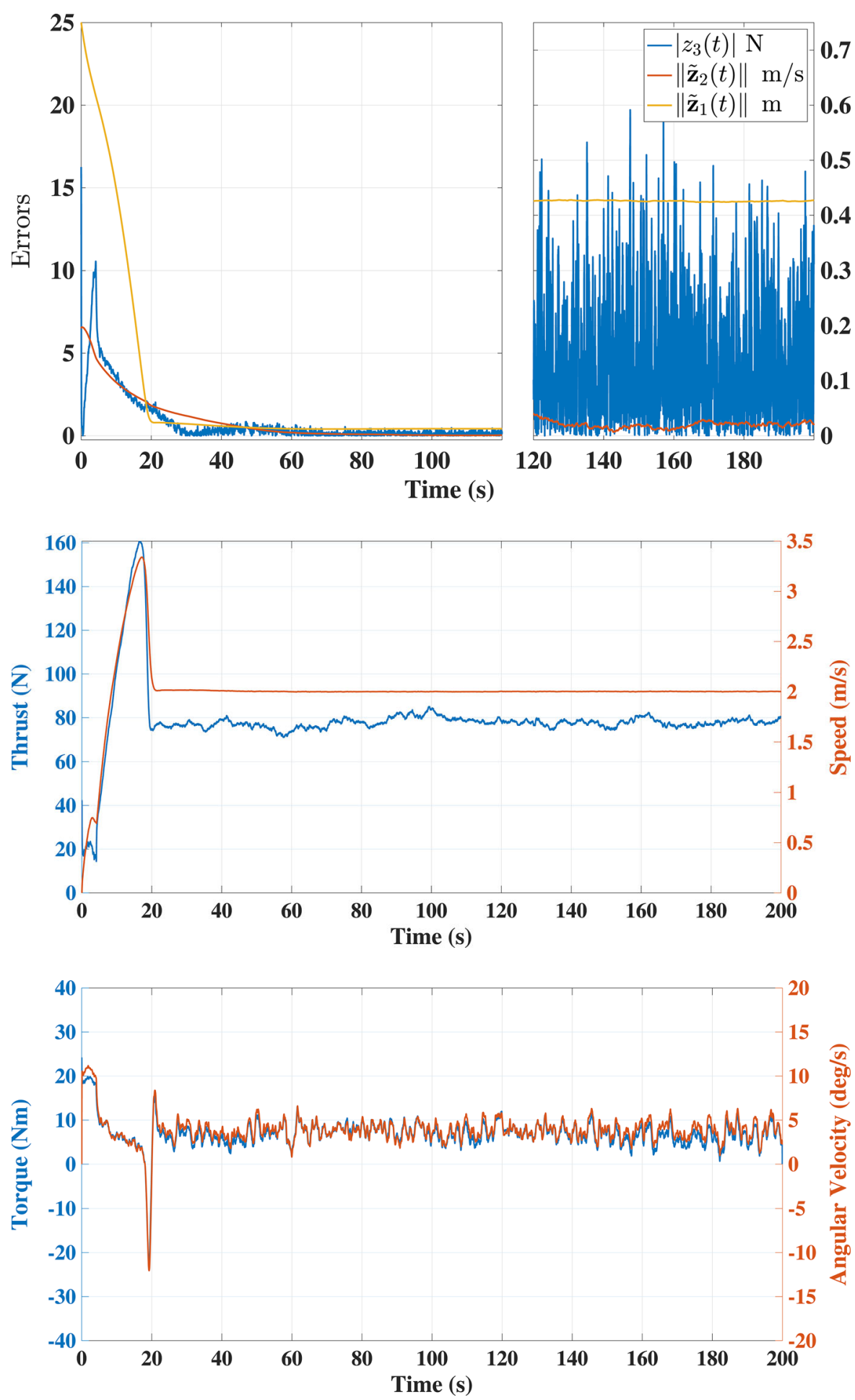
Publisher's Note Springer Nature remains neutral with regard to jurisdictional claims in published maps and institutional affiliations. 